\title{
BIG-FIVE OR BIG-SIX? \\ A ROMANIAN EXPLORATORY STUDY BASED ON A NONVERBAL MEASURE
}

\author{
Mihaela Minulescu ${ }^{1}$ \\ Universitatea Spiru Haret
}

\begin{abstract}
The Five-Factor Nonverbal Personality Questionnaire, FF-NPQ (Paunonen, Ashton \& Johnston, 2001) is an psychometric, structured, nonverbal measure of personality traits defined within the Big-Five model of personality (Costa \& McCrae, 1992). The questionnaire has been experimented on Romanian population and the psychometric properties have been studied on a normative sample of 1800 subjects (lliescu, Minulescu, Nedelcea, 2005). This study presents the results of an exploratory factorial analysis that was carried out in Romania on the items of the Five-Factor Nonverbal Personality Inventory (FFNPQ). The article is focused on the emergence of a 6-factor factorial solution, in some points different from Costa and McCrae's (1992) model, which has been the fundament of FFNPQ construction.
\end{abstract}

Chestionarul nonverbal de personalitate cu 5 factori, FFNPQ (Paunonen, Ashton \& Johnston, 2001) este unul psihometric, structurat, o măsură nonverbală a trăsăturilor de personalitate definită în modelul Marele 5 al personalității (Costa \& McCrae, 1992). Chestionarul a fost experimentat de populația română şi proprietățile psihometrice au fost studiate pe un eşantion normativ de 1800 subiecți (lliescu, Minulescu, Nedelcea, 2005). Acest studiu prezintă rezultatele unei analize factoriale exploratorii care a fost îndeplinită în România pe itemi al inventarului nonverbal de personalitate cu 5 factori (FFNPQ). Acest articol este focalizat pe soluția de ieşire a 6 factori de fabrică, în anumite puncte diferit de modelul lui Costa şi McCrae (1992), care a fost fundament la construcția FFNPQ-ului.

Key-words: personalitate, chestionare nonverbale, analiză factorială, Marele 5

\section{INTRODUCTION}

One of the current issues in scientific debates on personality is the cross-cultural validity and universality of the Big Five paradigm. A large part of studies in early nineteen's have replicated in different language families the same five-factor model underlining the personality structure: USA (Goldberg, 1981; John, 1990; Costa \& McCrae, 1985), Germany (Angleitner, Ostendorf \& John, 1990), Holland (Hofstee, W. K. B., 1990, De Raad, 1992), Italy (Perugini, Leone, Galluci, Lauriola, 1994; van Heck, Perugini, Caprara, Froger, 1994; Caprara, Barbaranelli, \& Comrey,1995), Spain ( Silva, Avia, Sanz \& al, 1994), France (Marvielde, 1994), Hungary (De Raad \& Smiszek, 1994), Croatia (Mlacic \&

\footnotetext{
${ }^{1}$ Adresa de contact: mminulescu@rdslink.ro
}

Knezovic, 1994), Solomon islands and India (White, 1980), dialects from Japan (Bond, 1979; Bond \& Forgas, 1984), Filipines (Church \& Katigbak, 1989 cf. Angleitner 1990) etc. Costa and McCrae assessed the cross-cultural generalizability of five-factor model using data from translations of NEO PI R in 5 distinct language families in comparison with American factor structure (McCrae, Costa, 1997, 1998). Minulescu (1996) reviews this evidence concluding the structure of individual differences in personality is uniform across several cultures: „All of them underlined optimum factorial structures of five super factors although the standard selection methodology (of the items) was not used by all. Of course the factorial solutions are different, especially in terms of significance and order..." (p. 138) 
However, in some of those studies the emergent factorial model consisted of 6 or 7 "big factors", and the general explanation focused on the cultural factor underlining personality (Zhou \& Wang, China, 2005, 7 factors collected with the FFNPQ ; Wang \& Cui, 2002, 2004, 7 factor using a standard verbal methodology). An earlier study, reported a 6 factor structure, with Conscientiousness factor splitting into an Achievement factor and a Methodicalness factor (Jackson D.N., Paunonen S.P., Fraboni M., D.Goffin R.D., 1996).

Some recent developments introducing the higher order factor analyses suggests that is possible to reduce the five to only two broader factor (Block, 2001).

With FFNPQ, the lexical perspective and the nonverbal perspective have been challenged as equally capable to elicit the fivefactor solution. The present study allows a trial on this last hypothesis and brings forward some explanations regarding the structure of factors emerging in the Romanian culture.

\section{PURPOSE OF THE PRESENT RESEARCH}

The present study offers additional data on the dispute regarding the universality of the Big Five model; the specific objective consisting in exploration of the factorial structure emerged in Romania based on data collected with the nonverbal items of the FFNPQ between 2004 and 2005 vs. the Romanian five factor structure emergent from the lexical approach (Minulescu, 1996, 2002, 2004).

\section{Materials}

The Five Factor Nonverbal Personality Questionnaire, FFNPQ (Paunonen, Jackson \& Ashton, 2004) is a structured omnibus nonverbal tool that offers a psychometric measure for the Big Five factors proposed by Costa \& McCrae (1992): N (Neuroticism), E
(Extraversion), O (Openness to Experience), A (Agreeableness) and $\mathrm{C}$ (Conscientiousness). The measure has 60 items, each of the 5 meta-factors being addressed by 12 items, these being $3 \times 9 \mathrm{~cm}$ drawings of actual behaviors. The answers to the items are collected by means of a 7-step Lickert scale. Psychometric data presented by the test authors on the basis of several studies (Paunonen, Ashton \& Jackson, 2001; Paunonen \& Ashton, 2002; Paunonen, Jackson \& Ashton, 2004) and by Romanian authors (Iliescu, Minulescu \& Nedelcea, 2005) are satisfactory and the questionnaire is without doubt a valid tool in a cross-cultural context. Studies carried out in Romania by the authors validate both the psychometric value of the FFNPQ as well as its cross-cultural coherence in measuring the Big Five model.

Internal consistency is the most commonly used index of the reliability of tests and measures. Internal consistency, calculated as coefficient alpha, can be roughly understood as the degree to which items in a scale measure the same thing, are homogeneous.

The first cross-cultural studies with FFNPQ addressed a sample of 701 students from seven countries: Canada, Finland, Germany, Norway, Poland and Russia (Paunonen \& al. 2001; Paunonen \& Ashton, 2002). The authors concluded FFNPQ is adequate for cross-cultural studies. Means of internal consistency Alpha indices of the seven countries have very similar values for the five scales, ranged from .66 to .77 . The translation of FFNPQ and experimentation on Romanian 1800 subjects sample reported very similar values with the five scales, ranged from .50 to .75 , with a mean of .68 . These values are acceptable for scales with 8 to 12 items. The authors concluded FFNPQ to be a reliable test and measure (lliescu, Minulescu, Nedelcea, 2005).

Table 1. Internal Consistency of five FFNPQ scales, international samples vs. Romanian sample

\begin{tabular}{lcc}
\hline FF-NPQ scale & Means of internal Consistency ${ }^{* *}$ & Internal Consistency for Romanian sample \\
\hline Extraversion & 0.75 & 0.74 \\
Agreeability & 0.72 & 0.69 \\
Conscientiousness & 0.71 & 0.73 \\
Neuroticism $^{*}$ & 0.64 & 0.50 \\
Openness & 0.77 & 0.75 \\
\hline
\end{tabular}

${ }^{*}$ The FF-NPQ scales have all 12 items, except for Neuroticism with only 8 items.

${ }^{* *}$ Every alpha coefficient is a mean of 7 countries coefficients under study. (Paunonen, Jackson \& Ashton, 2004, p. 37).

${ }^{* \star *}$ Internal consistency indices have been computed for 900 women and 900 men with age over 12 . 
The Romanian lexical replication (Minulescu, 1996, 2002, 2004) followed the classical research approach (John, Angleitner \& Ostendorf, 1988, De Raad, 1992) concluding to a five-factor solution: Extraversion, Immaturity, Agreeability, Conscientiousness, and Self Actualization. Principal components are covering of $68.6 \%$ the data variance: Extraversion $21.2 \%$, Immaturity $14.2 \%$, Agreeability $13.1 \%$, Conscientiousness $11.4 \%$, and Self Actualization 8.6\%

\section{Factor analysis}

The factor analytical process is based on the answers obtained from the Romanian normative sample of $\mathrm{N}=1800$ subjects $(\mathrm{N}=900$ men and $\mathrm{N}=900$ women). The sample is representative for the Romanian population aged over 12 years. The sampling method used was random sampling with an additional quota control on demographic parameters. The variables controlled in the sampling are gender, age, education and urban/rural area; the sampling error is $<3 \%$.

The initial factorial solution obtained by extracting the principal components from the 60 items of the test is unexpectedly complex. It is a solution on 16 factors, three of them having clear significance for the construct of Neuroticism $(\mathrm{N})$, three referring to specific facets of Extraversion (E), two being specific for Openness to Experience $(O)$, three for Agreeableness (A) and one for
Conscientiousness $(C)$. The other factors have a rather unusual meaning, combining specific facets for different dimensions, for instance $O$ and $\mathrm{C}$ or $\mathrm{A}$ and $\mathrm{E}$.

The initial 16 factor solution was submitted further to a second-order factor analysis, a procedure used also by de Marsh \& Hocevar (1985) and Marsh \& Richards (1987) in similar cases when the dimensions of the original factors were doubtful or impossible to grasp clearly. Such a procedure allows to maintain untouched the initial 16 components, while also offering important leads on discovering their psychological meaning of these components, in relation to the five classic dimensions.

The method employed was again the extraction of principal components, followed by a Varimax rotation with Kaiser Normalization. The second-order solution resulted in six components, covering $58,07 \%$ of the data variance. Out of the six components, five clearly outline the Big Five dimensions and the sixth is a factor combining meanings of $\mathrm{N}$ and $-\mathrm{C}$. We will in the following refer to these secondary factors with Roman numerals from I to $\mathrm{VI}$.

\section{RESULTS}

The synthetic presentation of the factorial structure is given in Table 2.

Table 2. Factorial structure of the FFNPQ in Romania

\begin{tabular}{|c|c|c|c|c|c|c|c|c|}
\hline & & Items & C & $\mathrm{N}$ & 0 & A & $E$ & I \\
\hline & & & $17.64 \%$ & $11.13 \%$ & $8.59 \%$ & $7.64 \%$ & $6.58 \%$ & 6.49 \\
\hline F1 & Achievement through study & 7 & 0.56 & & & & & \\
\hline $\mathrm{F} 2$ & Aggressiveness & 6 & -0.80 & & & & & \\
\hline F3 & Influence via humor & 9 & -0.71 & & & & & \\
\hline F7 & Care & 6 & 0.65 & & & & & \\
\hline F9 & Order & 3 & 0.64 & & -0.38 & & & \\
\hline F5 & Phobia & 5 & & 0.77 & & & & \\
\hline F8 & Anxiety & 4 & & 0.74 & & & & \\
\hline F10 & Need of support & 2 & & 0.48 & & 0.30 & & \\
\hline F4 & Variety of interests & 7 & & & 0.74 & & & \\
\hline F13 & Gregariousness & 2 & & -0.31 & -0.61 & 0.32 & & \\
\hline F6 & Solitude in nature & 4 & & & 0.38 & 0.56 & & \\
\hline $\mathrm{F} 11$ & Helpfulness & 2 & & & & 0.51 & & \\
\hline F14 & Lack of care for others & 2 & & & & 0.65 & & \\
\hline $\mathrm{F} 12$ & Leadership & 3 & & & & & 0.86 & \\
\hline F15 & Intolerance to failure & 1 & & & & & & 0.66 \\
\hline F16 & Failure in learning & 8 & & & & & & 0.75 \\
\hline
\end{tabular}

FFNPQ is clearly able to assess Big Five dimensions, even if in a global manner and without detecting the facets indicated by Costa \& McCrae (1992), each of the 
dimensions being clearly marked in the final factorial solution. Some of the five dimensions are more detailed, more emphasized, as it is the case of Conscientiousness, while others, like the emergence of Extraversion, are rather sketchy and incomplete, limited to only one facet. The rank order in terms of variance is different from FFNPQ, with Conscientiousness the first factor, Neuroticism the second, followed by Openness, Agreeableness and Extraversion and the sixth factor, Intolerance.

\section{Factor I. Conscientiousness}

This first factor covers $17.64 \%$ of the data variance and joins the following primary factors: F1 - Achievement through study (0.56), F2 - Aggressiveness (-0.80), F3 - Influence via humor (-0.71), F7 - Care (0.65) and F9 - Order (0.64)

This factor mingles the conformism and conscientiousness concepts in a pro-social way, with some contents related to:"what one should do", what"is right to do", inclination for study, and for order; care, especially for children but also for one's own person, for the personal environment, and for close acquaintances, friends, career. The factor also suggests the lack of aggressiveness and a penchant for a conventional, common behavior, coupled with a strong negative feeling towards being the centre of attention in jokes, humorous puns or at parties.

F1. Self accomplishment through education has a loading of 0.56 and is a facet reflecting conscientiousness in studying, the desire for notable intellectual performances, and capacity of studying hard, in a structured school system.

This facet has 7 items, the FFNPQ items $8,18,28,30,38,43,53$. The items have contents related to the capacity for a structured and constant effort, dreams of self accomplishment $(8,43,53)$, emphasis on order (18), and long term and constant labor (28), interest for studying $(30,38,43,53)$.

The capacity for studying hard in order to achieve self accomplishment is therefore an obvious dimension for Conscientiousness.

F2. Aggressiveness, with a negative loading of -0.80 on the Conscientiousness factor, is a facet of aggressiveness in interpersonal contexts and towards animals; the relevant behavior for the $\mathrm{C}$ factor are the low scores.

This facet contains 6 items: $11,12,22$, 32,42 , and 52 . The content of the items refer exclusively to aggressive behaviors towards other people or animals, except for item 11 that refers to leading a demonstration, based on a dominant leadership model.

Items 2, 27, 36, 57, although loading over .30 the Aggressiveness factor, have bigger or similar factorial loadings on other factors and facets, shaping as such the meaning of the Aggressiveness facet. Item 2 has the major loading on facet $\mathrm{F} 15$ (Intolerance to loss), included in Factor VI (Intolerance to failure) and the content is related to an aggressive emotional response in competitive settings. Item 27 has a similar loading on facet F14 (Carelessness for the others), corresponding to the Agreeableness dimension and a content related to the care for sick people. Item 36 has a major loading on facet F14 (Lack of care for others) corresponding to the Agreeableness dimension and a content related to the care for children.

F3. Influence via humor, with a loading of -0.71 on the dimension Conscientiousness is a facet describing persons who would dearly like to be the centre of social attention and who use to this end humor, puns and exhibitive behaviors. The relevant score for factor I are the low scores of this facet.

Facet F3 has 9 items: 6, 16, 26, 36, 46,51 , and 56 . The content of the items refer to: partying, one's accomplishments being acknowledged in public, playing with others, making a show of oneself in front of a group, group meetings, having fun. The negative loading on the Conscientiousness dimension underlines that persons with high scores on this facet have rather the tendency of opposing or eluding the common code of conduct through exhibitionism or humor, and are probably opposed to conventionalism, order and social conformity.

Items 1 and 11 , loading above 0.30 on this facet, have also major factorial loadings on other factors, thus additionally shaping the meaning of the facet F3. Item 1 has a bigger loading (.36) on facet F13 (Gregariousness), allocated to the Openness dimension and the content is related to one being the host of a party. Item 11 has major loading on facet F2 (Aggressiveness), also on the Conscientiousness dimension and the content is related to leading others, respectively being the leader of a demonstration.

F7. Care, with a loading of 0.65 on the first factor (Conscientiousness), identifies nurturing persons, especially those exhibiting care for children, but also with a high preference for feminine interests, or interests related to taking care of others. 
Facet F7 has 6 items: 7, 17, 37, 45, 47, and 58. The content and significance of the items is related to taking care of children or developing activities for children (excursions) as well as domestic/ household activities (item 45).

Items 47 and 58, although loaded over 0.30 on the Care facet, have major factorial loadings on other factors, thus additionally shaping the meanings of facet F7. Item 47 has a major loading on facet F11 (Helpfulness) allocated to the Agreeableness dimension and the content is related to a serviceable interpersonal behavior. Item 58 has a major loading on the Order facet (F9), also allocated to the Conscientiousness dimension and a content related to a highly ordered behavior.

F9. Order, with a loading of 0.64 on the Conscientiousness dimension, identifies persons who are very conscious in tiding up and keeping clean. Those individuals have a very ordered and coherent manner, both in terms of their own behavior and in a relational context. They have high intolerance to mess and a reactive behavior to the lack of neatness in others.

The F9 facet comprises 3 items: 3,33 and 58. All the contents of these items are convergent, describing states of an ordered behavior, either expressed in terms of one's own behavior, or in relation to the environment or to those around.

\section{Factor II. Neuroticism}

Factor II covers $11.13 \%$ of data variance and consists of facets F5 -Phobia (0.77), F8 - Anxiety (0.74) and F10 - Need for help (0.48). Factor II is a dimension for emotional instability and vulnerability, translated in fear, anxiety, sadness, refuse of social participation, desperate search for social support, a self-defeating attitude, feelings of helplessness and interpersonal dependency.

It is probably worth mentioning that among the other facets shaping the Neuroticism we have primary factor F13 Gregariousness, which has its primary loading on the Openness dimension $(-0.61$ as compared to -0.31 on the $\mathrm{N}$ dimension); it also shapes factor $\mathrm{N}$, as getting social support depends on the presence of the subject in social contexts and consists most of the time in having a social oriented, gregarious behavior.

F5. Phobia, with a loading of 0.77 on Neuroticism, identifies persons with very specific object fears.

Facet F5 has 5 items: 4, 24, 34, 44 and 55. The contents of those items refer to specific fears, fear of spiders (24), snakes (44), and mice (4) as well as nightmares and threatening daydreams $(34,55)$.

Item 55 has a similar loading on facet F8 (Anxiety), thus emphasizing the psychological meaning of the scale, as phobic reactions represent a sub-class of anxiety.

F8. Anxiety, with a loading of 0.74 is a primary factor for unspecific anxiety, distinguishing persons with unspecific fears, distrust, need for support and sleeping disorders.

Facet F8 has 4 items: 9, 14, 29 and 49. Their contents refer to insomnia (9), distrust and suspicion against others (14), need for social support $(29,49)$. This factor is obviously one of irrational fears, a generic factor of anxiety; although a paranoid aspect might be involved. The items related to need of support, also shape an interpersonal dependency level, specific also for agoraphobics.

Although having significant loadings on the Anxiety facet, items 34 and 55 contribute with bigger loadings on facet F5 (Phobia). Through their contents related to nightmares and threatening daydreams with the subjects as main character, the two items clearly emphasize the inner anxiety.

F10. Need of support, with a loading of 0.48 on the $\mathrm{N}$ dimension, is a very interesting primary factor, identifying persons with a high level of need for social support, with feelings of helplessness and even a high level of interpersonal dependence.

The F10 facet has only two pure items: 39 and 59. The contents of these items refer to support and encouraging behaviors expressed by others in situations of personal failure (in exams, love etc.), indicating the need and desire to look for social support. Thus, facet F10 would identify persons who depend on the support of those close to them, in order to cope with straining situations, with an implicit meaning of interpersonal dependence.

Item 49 has a higher loading $(0.45$ as compared to 0.42 ) on facet F8 (Anxiety) and a content that strengthens the meaning related to the need for social support.

Therefore, we denominate factor F10 "need for support". All its items come from the homonymous scale of the NPQ (Paunonen, Jackson \& Ashton, 2002), thus confirming, as a secondary conclusion, the factorial stability of the latter.

Factor III. Openness to Experience 
Factor III covers $8.59 \%$ of the data variance and combines the primary factors F4 Variety of interests (0.74) and F13 Gregariousness (-0.61). The primary factors F6 and $\mathrm{F} 9$ have also loadings on $\mathrm{O}$ (0.38 and 0.38 respectively), but with a primary loading on $A(0.56)$ and $C$ (0.64).

Openness to experience, as revealed in our study, is mainly a motivational dimension identifying intellectual interests, interests for nature and excursions in nature, openness to intellectual experiences. It has also a component indicating the preference for loneliness, as shown by the negative high loading $(-0.61)$ of the F13 facet (Gregariousness).

F4. Variety of interests, with a loading of 0.74 , identifies individuals with a structure of interests equally various and intellectually oriented, based mainly on a strong need for knowledge.

Facet F4 has 7 items: 5, 15, 40, 50, 54 and 60 . Their contents suggest to very varied and mainly intellectual interests, connected with nature, arts, natural sciences. All items have convergent meanings, obviously shaping a facet related to the structure of one's interests.

Item 45 has a higher loading $(0.35$ as compared to 0.33 ) on facet F7 (Care) and the content is related to washing laundry in the nature, a feminine domestic activity.

F13. Gregariousness, with a loading of -0.61 identifies for Openness persons who do not enjoy being in proximity with humans, part of a group. F13 is a contributor to nevrotism (lack of) and to agreeability in its positive meaning. We would have expected the Gregariousness dimension to score under the Extraversion factor, as it was the case for most of Big Five models up to now.

The F13 facet has 3 items: 1, 21 and 23. Their contents are related to socialization, pleasure of working with others, of enjoying time with others, of just being within a social situation. Item 23 has a content related to the refuse of continuing a solitary job (in expectation of achievements/ future rewards), when colleagues are having fun.

\section{Factor IV. Sensitivity}

Factor IV covers $7,64 \%$ of data variance and is comprised of factors F6 Solitude in nature (0.56), F11 - Helpfulness (0.51) and F14 - Lack of care for the others (0.65). This is a factor of emotional sensitivity, capturing a specific meaning of Agreeableness: empathy, the tendency of being close to others, of being nurturing and helpful. It identifies individuals with a kind and friendly behavior, interested in the positive quality of emotions.

Facets F10 (Need for support) and F13 (Gregariousness) have both loadings on this factor. They have, however, primary loadings on $\mathrm{N}(0.48)$ and $\mathrm{O}(-0.61)$ dimensions respectively, the loadings on the Sensitivity dimension ( 0.30 and 0.32 ) being smaller. These facets are additionally shaping the meanings of the Sensitivity factor with their content.

F6. Solitude in nature, with a loading of 0.56 , is a factor indicating the preference for travels in the nature and solitude, so it identifies persons with sensitivity and receptivity for the experience of natural environments.

Facet F6 has 4 items: 10, 20, 25 and 35. The content of the items is related to the solitary experience of nature. Item 5 has a major loading on facet F4 (Variety of interests), under the Openness dimension, but loads also 0.30 on this facet; its content refers also to solitary experiences in the nature, but rather as scientific knowledge and research of nature.

F11. Helpfulness, with a loading of 0.51 is a factor that groups nurturing behavior towards others, even when they display deviant behaviors. The factor captures a way of being kind, identifying individuals willing to help others even if this is not directly asked for.

Facet F11 has 2 items: 47 and 48. The content of the items is related to kind and helping behaviors towards others. Item 48 has an additional content related to order.

F14. Lack of care for others, with a loading of 0.65 is a factor somehow unusual, as by its meaning it is a kind of negative "left over" from factor F7 (Care). It is a factor grouping rather non empathic behaviors and responses, in the way of toughness and carelessness about others. It also indicates a behavior lacking emotional resonance.

Facet F14 has 2 items: 27 and 57 . The content of the items refers to aggressive responses or bantering persons who are in situations of suffering or personal failure, thus mandating its name.

\section{Factor V. Extraversion}

Factor $\mathrm{V}$ covers $6,58 \%$ of data variance and contains the F12 - Leadership primary factor.

It is a factor related to leadership, identifying individuals with an active need for emotional rewards generated by social 
involvement, with a high assertiveness and a need of social recognition.

F12. Leadership, with a loading of 0.86 is a factor defining the pleasure of leading others, of being in the centre of others' attention, the tendency of being seen as an example and the will of coordinating and supervising other people.

Facet F1 has 3 items: 13,31 and 41. Their contents refer to hard and constant work, public recognition of personal achievements and the pleasure of being at the head, of leading others. The facet actually combines 3 contents that define fundamental meanings of leadership; the propensity to leading involves the desire for social recognition and social conspicuousness.

Also, item 16, even while having a significant loading on this facet, has a major loading on the F3 factor (Influence via humor), allocated to the Conscientiousness dimension and a content related to the public recognition of personal achievements, thus further consolidating the interpersonal meaning of this facet.

\section{Factor VI. Intolerance to Failure}

Factor VI covers $6,49 \%$ of data variance and groups the facets F15 Intolerance to failure $(0.66)$ and F16 - Failure in learning (0.75). Factor VI does not relate with any of the classical Big Five dimensions. It is a factor of failure in interpersonal context, a failure in the desire of self-fulfilling, and failure in learning and academic achievement and it identifies individuals with a high awareness for the concept of failure or otherwise negatively influenced by failure.

F15. Intolerance to loss, with a loading of 0.66 is a factor that emphasizes the difficulty in accepting the very idea of loss in competitions, even though the stake is not real or important. This facet identifies persons who do not enjoy losing and who display aggressive manifestations to loss.

Facet F15 has only one item (3), with a content related to aggressive responses to loss in a sportive competition. Item 3 have also a loading of 0.35 on Aggressiveness, allocated to the Conscientiousness dimension, thus shaping the meaning of the F15 facet with a touch of aggressive behavior.

F16. Failure in learning, with a loading of 0.75 , has an opposite meaning to the F1 (Achievement/ Study) factor, allocated on the Conscientiousness dimension. It is a facet of failure in learning and academic achievement and has only one item, 19, with a content related to rejection due to failure. Although the factor has no significant meaning on any of the classical Big Five dimensions, we consider that it has rather a meaning associated to $\mathrm{N}$ (Neuroticism).

Item 8 have the major loading on the

F1 facet (Achievement through study) allocated to the $\mathrm{C}$ dimension, although it has also a loading higher than 0.30 on the Failure. This item is supplementing the significance of the facet with a content related to failure in studying, failure in school or in academic accomplishments.

\section{DISCUSSION AND COMPARISONS}

Obviously, in terms of facets and contents combined under each of the 6 factors, we finally have a global portrait significantly differing from Costa \& McCrae's (1992) model that was the starting point for constructing the FFNPQ; the structure of the original fivefactors is significantly different.

Conscientiousness, which is the most explicit dimension in the present research, retains only one common facet with the NEO$\mathrm{PI}-\mathrm{R}, \mathrm{F} 9$ (Care). Facet F2 (Aggressiveness) allocated to the Conscientiousness dimension with a negative loading, does not appear as such in the Costa \& McCrae (1992) solution, where opposite behaviors are combined on the Hostility facet allocated to Neuroticism, or to low scores on Agreeableness. The negative loadings of aggressiveness should be seen as denial of aggressive in the context of being conscientious. In Romanian lexical solution, aggressiveness is a major component of the second ranked factor, Immaturity.

The F3 facet (Influence via humor), that is found with a negative loading in the content of the Conscientiousness factor, includes a category of meanings that is not captured in the classical Big Five model, and is more prominent in the Romanian culture. On the other hand, in the lexical approach, humor is a positive facet (with markers such as: practical joker, humorous, genial, flexible, open minded) and appears as a Romanian specific to Extraversion (E3). In nonverbal terms, humor seems to be connected with the denial of need of being the centre of attention by humor, and by the usage of humor and of playful spirits in order to socialize and to obtain social support. It also contains an aspect related to a slight deviance from social norms, like for example high alcohol consumption in parties. 
Facet F7 (Care) is grouped on the Conscientiousness factor, although similar contents are usually allocated rather to Agreeability. This condition seems to support the cultural hypothesis, as the care for other people, especially children, older and sick people is a behavioral component strongly valued in the traditional role models of Romanian culture and even in the Orthodox religion, recognizable also as such in a series of moral norms, roles and attitudes delineating those behaviors that gain social respect and those that don't.

On the Neuroticism dimension one may also find a classical facet, F8 (Anxiety). Facets F5 (Phobia) and F10 (Need of help), also components of Neuroticism in our research, are not to be found in the classical Neuroticism factor, this could also signal a cultural determination of personality.

The Openness to Experience dimension is completely different from the one in the NEO-PI-R solution, combining aspects related to a variety of interests and to openness in one's social and interpersonal life. In the current factor analyses solution, facet F13 (Gregariousness), belonging to Extraversion in NEO-PI-R, is allocated to Openness. The F13 facet additionally loads more than 0.30 on two other factors, Neuroticism and Agreeability. Facet F4 (Variety of interests) may be considered as a global estimator for Openness to experience, as such a divergent approach of interests would probably also favor the variety and multitude of experiences. The lexical approach also reveled facets connected with Selfactualization consistent with F4: in depth thinking, openness, sophistication, independence and creativity.

The Sensitivity dimension corresponding to Agreeability (A) in the NEOPI-R Big Five solution has no common facet in this solution, although contents related to $\mathrm{F} 11$ (Helpfulness) and F14 (Lack of care for others) may be found in the classical approach. Sensitivity has a particular facet in the present study, the one related to solitude in nature (F6). Most likely, the meanings of solitude embedded in the items of this facet determined the fact that F6 it is part of the Sensitivity factor rather than of Openness to experience. The meaning of the factor is shaped by interrelation with others with $\mathrm{F} 13$ and $\mathrm{F} 14$ secondary loadings.

Extraversion is represented in the present study by a single facet (Leadership) and is the least shaped dimension of the five. It is surprising that, although the primary factorial analysis identified 3 components, F12 (Leadership), F13 (Gregariousness) and F3 (Influence via humor), that are normally assimilated with their contents to Extraversion; only one of them had a relevant loading on the Extraversion dimension. This suggests that relatively similar behaviors might be related to different personality constructs in different cultures.

In lexical replication Extraversion is a first rank factor with activism, optimism, humor, interpersonal ability and success seeking as facets. We consider that the differences in rank order and internal structure of Extraversion in nonverbal and verbal studies suggest the intervention of a mediating influence of projection in the generating of responses to figural items.

Intolerance to failure denominates the sixth factor. The six factor solution is different from most of the studies which emphasize the universal features of the Big Five model solution (Jackson, Paunonen, Fraboni \& Goffin, 1996); and especially different when compared to the five factors obtained by Minulescu (1996). Although factor VI is a residual factor, with a low loading, emphasizing meanings typical for $\mathrm{N}$ and (-) $\mathrm{C}$, it still underlines a different dimension of personality.

Intolerance to failure factor has psychological coherence as well as a specific historical and social resonance in the Romanian cultural context. As such, it is very likely to be connected to some real historical and social moments of the Romanian people and to be interpreted as an expression of a masochist feature, present in Romanian personality after centuries of domination and oppression.

In terms of cultural heritage, the Romanian of the XXI Century, after 50 years of communist conformist pressure and further 16 years of failure to adapt to social transition, continuously confronted with a value crisis, came to see Conscientiousness rather as control and conformism; Aggressiveness and humor have negative meanings especially because they underline the lack of behavioral control. Neuroticism is expressed by fear (with or without a specific trigger) and need for help. Openness is a focus on the own individuality: openness of interests, intellectual targets and lack of the need for social contacts. Agreeableness becomes rather a need for isolation, of personal emotional feelings, and is expressed by contents related to solitude in nature, sensitivity to the needs of others, as 
opposed to the lack of care for others. Extraversion is directly assimilated to social success and a leading position. Factor $\mathrm{VI}$ Intolerance to failure is underlining a substantial dimension of personal insecurity related to life.

Are the images much more a subject of peoples own projections, or are they indeed more objective in capturing the reality of the psychic structures? Are the inner factors subject to influence of long term socio-cultural influences?

These two questions have to be answered by specific research. The present study enforces the value of nonverbal instruments, such as FFNPQ, in multicultural studies. We should probably consider designing research projects specifically tailored to identify such influences in different cultures.

We are especially interested if the meanings allocated by respondents to the images of FFNPQ items are the same in different cultures, with the aim of identifying the items that better reflect the typicalities in each culture.

\section{References}

Angleitner, A., Ostendorf, F., John, O. P. (1990), Towards a Taxonomy of Personality Descriptors in German. A Psycho-lexical Study, European Journal of Personality, 4, 89-118;

Block J. (2001), Brief Report. Millennial Contrarianism: The five-Factor Approach to personality Description 5 years later. Journal of Research in Personality, 35, $98-107$

Caprara, G. V., Barbaranelli, C. \& Comrey, A.L. (1995). Factor Analysis of the NZEO-PI INventory and The Comrey Personality scales in an Italian sample,. Person. Individ. Diff, 18, 2, 193 - 2000

Costa, P. T. \& McCrae, R. R. (1985), The NEO Personality Inventory Manual, Odessa, Florida, Psychological Assessment Resources

Costa, P. T. Jr., \& McCrae, R. R. (1988). From catalogue to classification; Murray's needs and the five-factor model. Journal of Personality and Social Psychology, 55, 258265.

Costa, P.T. Jr., \& McCrae, R.R. (1992). Revised NEO Personality Inventory (NEOPI-R) and NEO Five-Factor Inventory (NEO-FFI) professional manual. Odessa, FL: Psychological Assessment Resources, Inc.

De Raad, B. (1992). The replicability of the Big Five personality dimensions in three word classes of the Dutch language. European Journal of Personality, 6, $15-29$

De Raad, B., Szirmak, Z. (1994), The Search for big-five in a non Indo-european language. The Hungarian Trait structure and its relationship to the EPQ and PTS, paper, The VIIth APP Conference, Madrid

Goldberg L.R. (1981), Language and Individual Differences: The search for universals in Personality Lexicons. In Wheeler L. (ed.), Review of Personality and Social Psychology,2,141-165

Heck van G.L., Perugini M., Caprara G.V., Froger J. (1994), The Big -five as Tendencies in situations. Person. Individ. Diff., 16, 5, 715 732

Hofstee, W. K. B., 1990, The Use of Everyday Language for Scientific Purpose, European Journal of Personality, 4, 77-88;

Iliescu, D., Minulescu, M. Nedelcea, C., (2005). The Nonverbal Personality Questionnaires. NPQ and FFNPQ: Technical and interpretative manual. Bucharest: Psihocover.

Jackson, D. N., Paunonen S.V., Fraboni M., Goffin R.D. (1996), A Five-factor vs. six-factor model of personality structure. Person. Individ, Diff., vol.20, No.1, 33-45

John, O. P., Angleitner, A., \& Ostendorf, F. (1988). The lexical approach to personality: a historical review of trait taxonomic research. European Journal of Personality, 2, 171 203

John, O. P. (1990), The "Big Five" Factor Taxonomy: Dimensions of Personality in the Natural Language and in Questionnaires, în Pervin, L. (ed.), Handbook of Personality Theory and Research, New York, Guilford, 66-100

Marsh, H.W. \& Hocevar, D. (1985). Application of confirmatory factor analysis to the study of self-concept: First and higher order factor models and their invariance across groups. Psychological Bulletin, 97, 562-582.

Marsh, H. W. \& Richards, G. E. (1987). The multidimensionality of the Rotter I-E scale and its higher-order structure: An application of confirmatory factor analysis. Multivariate Behavioral Research, 22, 39-69.

Marvielde, I.(1994), A comparison of Five Factor ratings and free description of children aged 3 to 12, Paper, The VIIth EAPP Conference, Madrid

McCrae R.R. \& Costa P.T., (1997), Personality Trait Structure as a Human Universal. American Psychologist, vol 52, no.5, 509-516

McCrae R.R., Costa P.T. jr., del Pilar G.H., Rolland J/P., Parker W.D. (1998), Cross-cultural assessment of the five factor model. The 
revised NEO Personality Inventory. Journal of Cross-Cultural Psychology, vol., 29, No.1, $171-188$

Minulescu, M. (1996), Replicarea modelului Big Five în limba română. Specificul socio-cultural exprimat în conținutul factorilor. Chestionarul ABCD-M. Zlate M. (Ed.); Psihologia vieții cotidiene. Iaşi, Polirom.

Minulescu, M. (2002), Replication of Big Five model in Romanian language. Paper. National Conference of Psychology, Neptun, Romania.

Minulescu, M. (2004). Modern psycho-diagnosis. Personality questionnaires. Editura Fundației România de Mâine, Bucureşti.

Mlacic, B. \& Knezovici Z. (1994), Big -Five studies in Croatia: a transparent vs opaque format, paper, The VIIth EAPP Conference, Madrid

Paunonen, S. V., \& Ashton, M. C. (2002). The nonverbal assessment of personality: The $N P Q$ and the FFNPQ. In De Raad, B., \& Perugini, M. (Eds.), Big Five assessment. Göttingen: Hogrefe \& Huber, 171-194.

Paunonen, S. V., Ashton, M. C., \& Jackson, D. N. (2001). Nonverbal assessment of the Big Five personality factors. European Journal of Personality, 15, 3-18.
Paunonen, S. V., Jackson, D. N., \& Ashton, M. C. (2002). Manual of the Nonverbal Personality Questionnaire, and the Five-Factor Nonverbal Personality Questionnaire. Port Huron, MI: Sigma Assessment Systems.

Paunonen, S. V., Jackson, D. N., \& Ashton, M. C. (2004). NPQ manual. Nonverbal Personality Questionnaire and Five-Factor Nonverbal Personality Questionnaire. Port Huron, MI: Sigma Assessment Systems.

Perugini, M., Leone, L., Galluci, M., Lauriola, M., (1994), Selection of a Short Adjective Check List to measure Big Five, paper, The VIlth EAPP Conference, Madrid

Silva, F., Avua, D., Sanz, J., Martines-Arias, R., Grana J.L., Sanchez-Bernardos, L. (1994), The five factor model - I. Contribution to the structure of the NEO-PI, Person. Individ. Diff., 17, 6, 741 - 753

Zhou, F., Wang, D. (2005). Will the Five-Factor model emerge? Assessing Chinese personality by a non-verbal scale. Testing International, 15, 1, 2-4.

White, G.M., 1980, Conceptual universals in interpersonal language, American Anthropologist, 82, 759 - 781. 